\title{
A systematic review of concussion in rugby league
}

\author{
Andrew Gardner, ${ }^{1}$ Grant L Iverson, ${ }^{2,3}$ Christopher R Levi, ${ }^{1}$ Peter W Schofield, ${ }^{1}$ \\ Frances Kay-Lambkin, ${ }^{1,4}$ Ryan M N Kohler, ${ }^{5}$ Peter Stanwell ${ }^{6}$
}

- Additional material is published online only. To view please visit the journal online (http://dx.doi.org/10.1136/ bjsports-2013-093102).

${ }^{1}$ Centre for Translational Neuroscience and Mental Health, School of Medicine and Public Health, University of Newcastle, Callaghan, New South Wales, Australia ${ }^{2}$ Department of Physical Medicine and Rehabilitation, Harvard Medical School, Boston, Massachusetts, USA ${ }^{3}$ Red Sox Foundation and Massachusetts General Hospital Home Base Program, Boston, Massachusetts, USA ${ }^{4}$ National Drug and Alcohol Research Centre, University of New South Wales, Sydney, Australia

${ }^{5}$ Australian Sports Commission, Australian Capital Territory, Canberra, Australia

${ }^{6}$ Faculty of Health \& Medicine, School of Health Sciences, University of Newcastle, Callaghan, New South Wales, Australia

\section{Corresponding to}

Dr Andrew Gardner, Centre for Translational Neuroscience and Mental Health, Level 5, McAuley Building, Calvary Mater Hospital, Waratah, NSW 2298, Australia; andrew. gardner@neurogard.com.au.

Received 7 October 2013 Revised 19 February 2014 Accepted 16 March 2014 Published Online First 10 April 2014

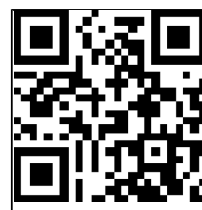

Editor's choice Scan to access more Scan to access m
free content

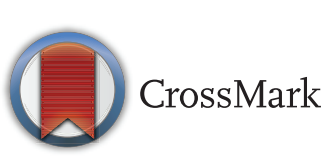

To cite: Gardner $A$, Iverson $\mathrm{GL}$, Levi $\mathrm{CR}$, et al. $\mathrm{Br}$ J Sports Med 2015;49 495-498.

\section{ABSTRACT}

Objectives Concussion remains one of the inherent risks of participation in rugby league. While other injuries incurred by rugby league players have been well studied, less focus and attention has been directed towards concussion.

Review method The current review examined all articles published in English from 1900 up to June 2013 pertaining to concussion in rugby league players.

Data sources Publications were retrieved via six databases using the key search terms: rugby league, league, football; in combination with injury terms: athletic injuries, concussion, sports concussion, sportsrelated concussion, brain concussion, brain injury, brain injuries, mild traumatic brain injury, mTBI, traumatic brain injury, TBI, craniocerebral trauma, head injury and brain damage. Observational, cohort, correlational, crosssectional and longitudinal studies were all included.

Results 199 rugby league injury publications were identified. $39(20 \%)$ were related in some way to concussion. Of the 39 identified articles, $6(15 \%)$ had the main aim of evaluating concussion, while the other 33 reported on concussion incidence as part of overall injury data analyses. Rugby league concussion incidence rates vary widely from 0.0 to $40.0 / 1000$ playing hours, depending on the definition of injury (time loss vs no time loss). The incidence rates vary across match play versus training session, seasons (winter vs summer) and playing position (forwards vs backs). The ball carrier has been found to be at greater risk for injury than tacklers. Concussion accounts for $29 \%$ of all injuries associated with illegal play, but only $9 \%$ of injuries sustained in legal play.

Conclusions In comparison with other collision sports, research evaluating concussion in rugby league is limited. With such limited published rugby league data, there are many aspects of concussion that require attention, and future research may be directed towards these unanswered questions.

\section{INTRODUCTION}

Originating in the north of England in the late 19th century, rugby league has become a popular team collision sport played throughout the world at a variety of competition levels. ${ }^{1}$ It is a physical sport involving numerous collisions and tackles. Each team, consisting of 13 players on the field, is allowed six tackles with the ball. The ball cannot be thrown forward but must be carried forward or kicked downfield. At the completion of each set of six tackles, the ball is immediately given to the opposing team to commence their set of six tackles. The same players therefore engage in offensive and defensive roles, depending on which team is in possession of the ball. The game is played non-stop, except for a serious player injury, for two $40 \mathrm{~min}$ halves. The overall objective of the game is to carry the ball over the goal line of the opponent to score a try. ${ }^{2}$ In Australia, rugby league is a popular contact sport. There are approximately 167533 registered players with 368869 involved in school competition and 893965 involved in development club programmes. ${ }^{3}$

With the improvements in professionalism and commercialisation of sports such as rugby league, an increase in the value of the athlete as a commodity has occurred. Injuries sustained by players are now of considerable financial importance to the individual player and to their club. Participation in rugby league, at any level, carries inherent risk for injury, ${ }^{4}$ including concussion.

Sport-related concussion is a common injury, ${ }^{5-7}$ and these injuries might be more prevalent than initially thought because some concussions go unrecognised. ${ }^{8}$ Approximately $90 \%$ of concussions in sport occur without loss of consciousness ${ }^{9-12}$; thus, they can be difficult to detect and might be underdiagnosed. Concussions are caused by accelerations or decelerations of the head involving linear (translational) and/or rotational forces, and there is tremendous interest in trying to better understand the biomechanics of this injury. ${ }^{13-17}$ Concussions have a large adverse effect on cognition and balance in the first $24 \mathrm{~h}$ following injury, with resolution of these deficits occurring within about 1 week according to group studies. ${ }^{18} 19$ There is evidence that a minority of athletes do not experience rapid recovery in cognitive functioning, ${ }^{20}$ and this subgroup might be obscured in statistical analyses applied to larger groups of athletes. ${ }^{21}$ Younger athletes might take longer to recover. In a prospective study of high school football players, ${ }^{22} 23$ approximately $42-47 \%$ were deemed functionally recovered by 1 week (see figure 1, p.503) $)^{23}$ and it was not until 4 weeks that $84-94 \%$ were considered recovered.

Concussion in sport has been the topic of media attention recently, thus raising awareness in the participants of collision sports, parents and the general community, and also sports medicine physicians and researchers. The aim of this review was to systematically evaluate the available evidence on concussion in rugby league.

\section{METHODS}

The review was conducted in two stages. In stage 1, articles were retrieved via online database searching, hand-searching reference lists and performing cited reference searches (see figure 1). The current review examined all articles published in English from 1900 up to June 2013 pertaining to concussion in rugby league athletes. The online databases of PubMed, PsycINFO, MEDLINE, EMBASE, SPORTDiscuss and Web of Science were searched, using the key 
search terms: rugby league, league, football; in combination with injury terms: athletic injuries, concussion, sports concussion, sports related concussion, brain concussion, brain injury, brain injuries, mild traumatic brain injury, mTBI, traumatic brain injury, TBI, craniocerebral trauma, head injury and brain damage. The reference lists of articles retrieved for inclusion in the review were searched to identify other relevant articles. Key articles retrieved via online databases and through hand-searching reference lists were also used for further searches using the Web of Science Cited Reference function. During stage 2, the titles and abstracts of articles were reviewed to assess eligibility for inclusion in this review. Articles were regarded as relevant and warranting inclusion if they were experimental studies examining concussed rugby league players. Studies were included whether they were conducted with acute or long-term concussed athletes (ie, there were no restrictions placed on time elapsed since injury) and independent of examination techniques used to assess these players (eg, neuroimaging, symptom checklist, balance testing or neuropsychological testing). Where there was uncertainty about whether a study should be included based on the review of the title and abstract, the full article was retrieved. Only observational, cohort, correlational, cross-sectional and longitudinal studies were included.
RESULTS

A total of 8639 articles were identified using the search strategy outlined in figure 1 . The initial search strategy was far-reaching and had limited restrictions, in order to identify all articles eligible for inclusion. Owing to the nature of the initial search, a considerable number of citations were not relevant largely due to the use of the term 'football', which yielded over 7500 citations pertaining to American football, rugby union, Australian football and/or 'soccer' research. After all identified citations were screened, 199 were retrieved and screened for eligibility. Of the 199 articles, 125 were not research studies (ie, conference presentation, abstract only and commentary), 28 were excluded on the basis that the participants were not athletes (ie, they were not sports-related concussion cases) and 7 duplicates were identified on closer inspection. The final outcome following this screening process resulted in the inclusion of 39 articles for this review (33 related to concussion incidence ${ }^{124-54}$ and 6 specifically examining concussion). ${ }^{55-60}$

There were 18 published articles that reported the incidence of concussion per 1000 playing hours ${ }^{1}$ $25 \quad 27-3136 \quad 37394047485155 \quad 61-63$ (see online supplementary table S2). Incidence rates varied widely from $0.0^{27} 31$ to

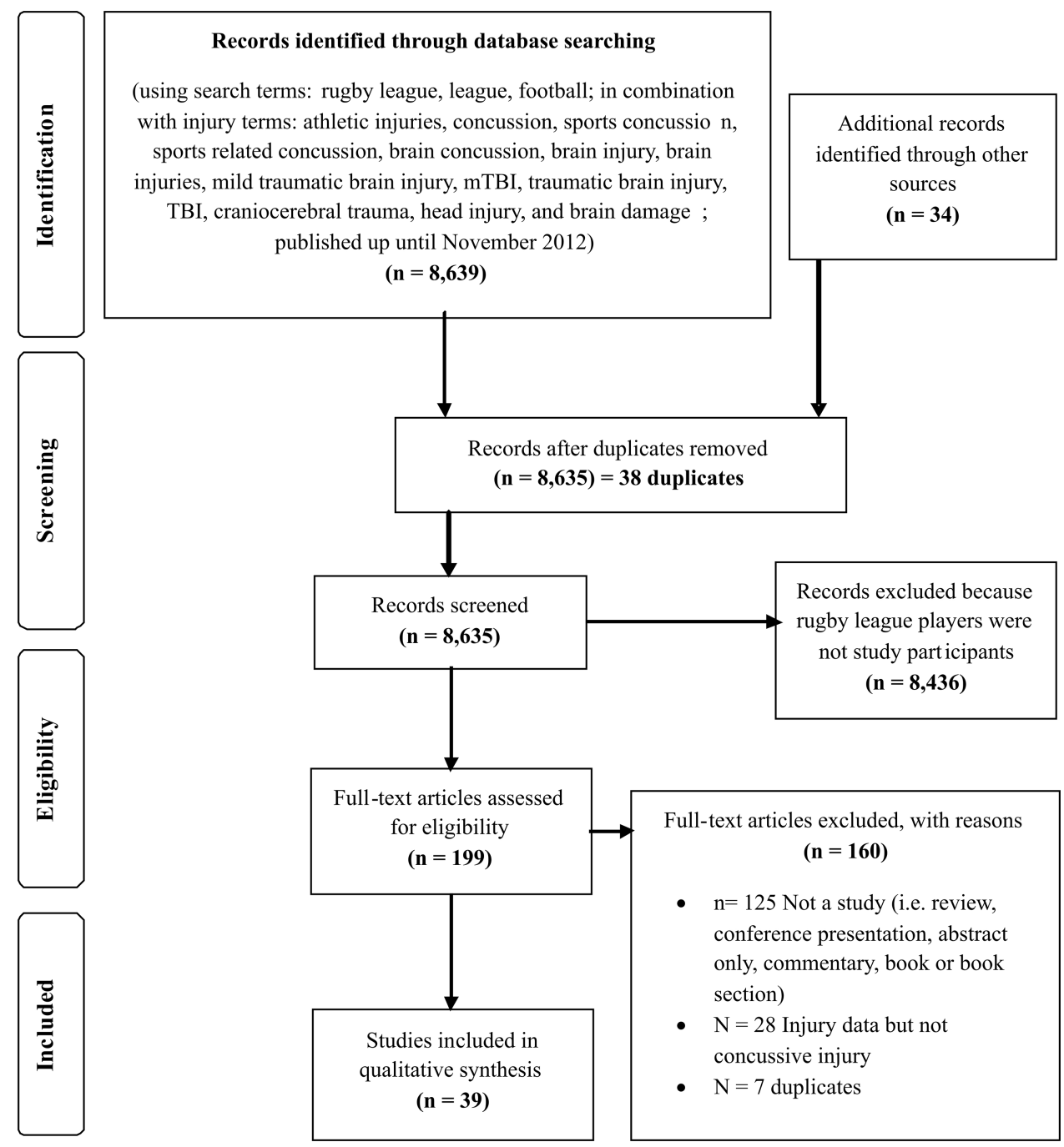

Figure 1 PRISMA flow diagram. 
approximately 40.0 , with differences in sampling and methodology most likely explaining a large amount of this variation. ${ }^{37}$ Concussions are less common in rugby league than other types of injuries such as contusions, muscular strains, joint injuries, abrasions and lacerations. ${ }^{4} 24283361$ The incidence of concussion has been observed to remain consistent over consecutive seasons. Between $13 \%$ and $17 \%$ of all players sustained a concussion over three consecutive seasons. ${ }^{55}$ However, studies on the incidence of injuries in rugby league are confounded by inconsistencies in the injury definitions used. Initial attempts at a standard definition for injury were not achieved, yet recently an international consensus opinion on the definition of injury has been accepted. ${ }^{4}$ Some studies used the strict criterion of a missed match (time loss) as the injury definition, and others used a medical treatment (non-time loss) to define the injury. These variations in the definition of injury are highlighted by considering that up to $85 \%$ of all playing injuries, and up to $82 \%$ of all training injuries, are 'non-time loss' injuries. Non-time loss concussions account for approximately $71 \%$ of all concussions ${ }^{46}$ suggesting that the most reliable studies in this body of literature estimate concussion incidence between 8.0 and 17.5 injuries/1000 playing hours. ${ }^{162}$

Tackling has been identified as the most common cause of concussion in rugby league, ${ }^{30} 3653$ with the tackled player reportedly more vulnerable to injury than those players making the tackle. ${ }^{61}$ It is therefore not surprising, given the reported forces induced on the bodies of players involved in the tackle, ${ }^{64}$ and the high number of tackles that occur in each game, ${ }^{61}$ that the incidence of concussion in rugby league is relatively high (see supplementary tables S1 and S2 for a review). Playing position (forwards vs backs) might also influence the risk for concussion. The forwards (who typically possess a bigger physique and are involved in more contact/tackles during the game) might be at greater risk for injury than backs. ${ }^{28}{ }^{40}$ King et al ${ }^{61}$ reported that the tackle-related concussion occurred most frequently to the ball carrier when tackled at the shoulder or midtorso height, in their blind vision, when involving two or more tacklers, and in the final quarter of matches. Of all injuries associated with illegal play, 29\% were concussions, whereas only $9 \%$ of injuries sustained in legal play were concussions. ${ }^{53}$

Compared with the rates of concussion during match play (34.6/1000 playing hours), one study reported that the rates of concussion during training were $0.3 / 1000$ playing hours. ${ }^{33}$ A reduction in training loads (ie, reduced by 1.7 vs $0.7 / 1000$ training hours) was also found to reduce the injury rates in rugby league players and resulted in greater improvements in maximal aerobic power. ${ }^{31}$ Another study reported 32-37 injuries/1000 playing hours compared with 1.0/1000 training hours by reducing training loads. ${ }^{37}$ Variations in concussion rates were also observed across seasons, with winter injuries occurring at a rate of 3.35/1000 playing hours and summer injuries at a rate of $2.51 / 1000$ playing hours, with a winter/summer risk ratio of $0.75 .^{39}$ Despite little attention being given to the possible effects of history of concussion, one study reported that $62 \%$ of concussed athletes had sustained a previous concussion. This study also found that $30 \%$ of players sustained a concussion in the current playing season. ${ }^{59}$ As a comparison, the rates of injuries during match play have been estimated to range between $1.68^{36}$ and $104.8^{27}$ for contusions, $9.2^{36}$ and $261.9^{27}$ for muscular strains, $12^{61}$ and $65.5^{27}$ for joint injuries, and $0^{27}$ and $40^{37}$ for concussions during $1000 \mathrm{~h}$ of match play.

In a New Zealand (NZ) economics study, concussions were associated with the highest mean cost per injury type, accounting for $6.3 \%$ of total injury costs, despite representing only
$1.8 \%$ of the total injury entitlement claims. ${ }^{61}$ The incidence of concussion varied among ethnicity, with NZ Maori $(n=62$; 10.4 injuries/1000 playing hours) recording significantly more concussions than other ethnic groups (NZ European: $n=41 ; 6.9$ injuries/1000 playing hours; Pacific people: $n=17 ; 2.9$ injuries/ 1000 playing hours; Asian: $n=0$ and others/unknown: $n=31$; 5.2 injuries/1000 playing hours). Total cost and mean cost per concussion was found to vary across ethnic groups in this study (NZ Maori: \$2 $363000 \mathrm{~N} \mathrm{Z}$ dollars (mean cost per concussion $\$ 38$ 118); NZ European: $\$ 86000$ (mean cost per concussion \$2097); Pacific people: $\$ 44000$ (mean cost per concussion \$2588); Asian: \$0 and others/unknown: \$239000 (mean cost per concussion $\$ 7709$ ). ${ }^{50}$

With respect to the level of knowledge among players and officials regarding concussion and the opinion of players regarding the importance of management, researchers reported that $54 \%$ knew of a concussion policy in rugby league but only $8 \%$ could identify the 3-week mandatory stand-down requirement, and 78\% reported a 7-day stand-down as the requirement for recovery from concussion. Loss of consciousness was reported to be required in the definition of concussion by $39 \%$ of respondents. Overall concussion knowledge was low at $42 \%( \pm 20 \%)$. Trainers/medics recorded the highest overall concussion knowledge. Misconceptions regarding this injury appear to be common. ${ }^{60}$ King et $a l^{49}$ reported that fewer than $34 \%$ of injured athletes sought medical clearance for return to sports participation for match play, and fewer than $25 \%$ for return to training. It was also reported that up to $75 \%$ of players felt that time off for rehabilitation was too long, especially for concussion with the 3-week mandatory stand-down period. ${ }^{49}$ Interestingly, a survey of club coaches found that $55 \%$ of respondents who had a player with a concussion $(n=52)$ had not sought medical clearance for a concussed player before returning them to match or training activities. ${ }^{60}$

The most thorough study until now has been conducted by Hinton-Bayre et $a l^{55}$ who examined the epidemiology and consequence of concussion in rugby league. The authors found that the incidence of concussion remained relatively stable across the three seasons of observation. They reported 9.84 concussions/ 1000 playing hours in first grade (the highest level of club competition); 7.87 concussions/1000 playing hours in reserve grade (the second tier of club competition) and 5.90 concussions/1000 playing hours in age-group $(\mathrm{u} / 21 \mathrm{~s}$ and $\mathrm{u} / 19 \mathrm{~s})$ competitions. Loss of consciousness occurred in only six cases (12\%), and individual players sustaining a subsequent injury accounted for seven (16\%) of all concussive injuries. Unlike previous studies, Hinton-Bayre, Geffen, and Friis did not observe any playing positions that were more vulnerable to concussion. Players in possession of the ball (players being tackled) were not concussed significantly more frequently than defensive players (players making the tackle). There were two recorded concussions that occurred when neither player in the collision had possession of the ball. The reported mechanisms of injury were as follows: $40 \%(n=17)$ head high tackles, 35\% ( $n=15)$ head contact with the ground and head contact with opposing player's body $(n=5)$. The most common self-reported postconcussion symptoms were as follows: headache $(n=35)$, unsteadiness $(n=22)$, visual disturbance $(n=19)$, dizziness $(n=11)$ and nausea $(n=10)$.

\section{DISCUSSION}

Concussions in rugby league are common. The incidence rates vary dramatically in large part due to how the injury has been defined across studies. However, using the more liberal injury definition, there appear to be between 8.0 and 17.1 injuries/ 
1000 playing hours. One study suggested that a substantial minority of athletes (eg, 13-17\%) will sustain this injury at least once over the course of three playing seasons. ${ }^{55}$ The rate of injury is much higher in match play than in training. ${ }^{33} 37$ There is some evidence that forwards are at greater risk for injury ${ }^{28}{ }^{40}$; the ball carrier appears to be statistically more likely to get injured than the tackling player. ${ }^{61}$ Concussion rates are disproportionately high for illegal play. ${ }^{53}$ This finding provides governing bodies of the sport with an opportunity to modify risk by implementing greater sanctions, which hopefully would modify the playing behaviour of participants and reduce concussion rates.

The definitions of concussion in past rugby league studies have not been consistent with international recommendations. ${ }^{65}$ Over the past decade, several agreement statements and consensus statements have set out standardised injury definitions for injury. ${ }^{66-71}$ In contrast, most rugby league studies have used a strict criterion of a missed match (time loss) as the injury definition, and a number of other studies have incorporated a less strict injury definition that includes the player merely receiving medical treatment (non-time loss). Future researchers are encouraged to use consensus-based definitions of this injury. ${ }^{71}$

The majority of rugby league studies addressed injury rates. There were only six studies that addressed other issues. The topics of these studies were diverse and mostly non-overlapping, including a comprehensive audit of concussion in rugby league, ${ }^{55}$ examination of the psychometric properties of screening $^{59}$ and cognitive tests in concussed rugby league footballers, ${ }^{56} 57$ retrospectively examining concussive convulsions ${ }^{58}$ and assessing concussion knowledge among rugby league club stakeholders. ${ }^{60}$ King et $a l^{60}$ found that misconceptions about concussion appear to be common in players, trainers and coaches. This highlights a weakness in the education of rugby league stakeholders and the importance of widespread education. Education dissemination could be a collaborative effort between the governing bodies and the elite level, which plays a crucial role in the filtering of all educational messages to the community and the grass-roots levels.

Research focused on studying the acute consequences and best management strategies in current players, and the potential longer term outcomes of concussion in retired players is needed. Future research could, for example, use video analysis to determine whether certain playing styles (eg, tackling, ball carrying or running techniques) or playing positions are associated with increased risk for injury. ${ }^{72-76}$ Future research in the areas of prevention, injury identification and medical management, and risk for long-term outcomes will be of benefit to current athletes, trainers and coaches.

\section{What are the new findings?}

- The incidence of concussion in rugby league varies considerably due to the lack of consensus regarding a 'definition of injury'.

- The rate of injury is much higher in match play than in training; the ball carrier appears to be statistically more likely to get injured than the tackling player, and injury rates are disproportionately high for illegal play.

- The current rugby league concussion literature is small, and further research is required across numerous areas and levels of competition.
Contributors AG developed the concept and methodology and also conducted the literature search and structure of the review. He wrote the entire content included in the manuscript, figures and tables. GLI assisted with the development of the concept and methodology. He also provided considerable editing assistance and comment on all sections, the figures and tables to finalise the manuscript. CRL, PWS, FK-L, RMNK and PS provided expert input to the final draft of the manuscript.

Competing interests $A G$ has a clinical practice in neuropsychology involving individuals who have sustained sports-related concussion (including current and former athletes). He has received travel funding from the Australian Football League (AFL) to present at the Concussion in Football Conference in 2013. Previous grant funding includes the NSW Sporting Injuries Committee, the Brain Foundation and the Hunter Medical Research Institute, supported by Jennie Thomas. GLI has been reimbursed by the government, professional scientific bodies and commercial organisations for discussing or presenting research relating to mild traumatic brain injury (TBI) and sport-related concussion at meetings, scientific conferences and symposiums. He has a clinical and consulting practice in forensic neuropsychology involving individuals who have sustained mild TBIs. He has received research funding from several test publishing companies, including ImPACT Applications, Inc, CNS Vital Signs and Psychological Assessment Resources (PAR, Inc). He is a coinvestigator, collaborator or consultant on grants relating to mild $\mathrm{TBI}$ funded by several organisations, including, but not limited to, the Canadian Institute of Health Research, Alcohol Beverage Medical Research Council, Rehabilitation Research and Development (RR\&D) Service of the US Department of Veterans Affairs, Vancouver Coastal Health Research Institute and Roche Diagnostics Canada.

Provenance and peer review Not commissioned; externally peer reviewed.

\section{REFERENCES}

1 King DA, Gissane C. Injuries in amateur rugby league matches in New Zealand: a comparison between a division 1 and a division 2 premier grade team. Clin J Sport Med 2009:19:277-81.

2 Hoskins W, Pollard $\mathrm{H}$, Hough $\mathrm{K}$, et al. Injury in rugby league. J Sci Med Sport 2006;9:46-56.

3 National Rugby League Annual Report 2012. Sydney: National Rugby League.

4 King DA, Hume PA, Milburn PD, et al. Match and training injuries in rugby league. Sports Med 2010;40:163-78

5 Koh JO, Cassidy D, Watkinson EJ. Incidence of concussion in contact sports: a systematic review of the evidence. Brain Inj 2003;17:901-17.

6 Delaney JS. Head injuries presenting to emergency departments in the United States from 1990 to 1999 for ice hockey, soccer, and football. Clin I Sport Med 2004; 14:80-7.

7 Powell JW, Barber-Foss KD. Traumatic brain injury in high school athletes. JAMA 1999;282:958-63.

8 McCrea M, Hammeke TA, Olsen G, et al. Unreported concussion in high school football players: implications for prevention. Clin J Sport Med 2004;14:13-17.

9 Macciocchi SN, Barth JT, Alves W, et al. Neuropsychological functioning and recovery after mild head injury in collegiate athletes. Neurosurgery 1996;39:510-14.

10 Guskiewicz KM, Weaver NL, Padua DA, et al. Epidemiology of concussion in collegiate and high school football players. Am J Sports Med 2000;28:643-50.

11 McCrea M, Guskiewicz KM, Marshall SW, et al. Acute effects of recovery time following concussion in collegiate football players: the NCAA Concussion Study. JAMA 2003;290:2556-63.

12 Meehan WP, d'Hemecourt P, Comstock RD. High school concussion in the 20082009 academic year: mechanism, symptoms, and management. Am J Sports Med 2010;38:2405-9.

13 Eckner JT, Oh YK, Joshi MS, et al. Effect of neck muscle strength and anticipatory cervical muscle activation on the kinematic response of the head to impulsive loads. Am J Sports Med 2014;42:566-76.

14 Wilcox BJ, Beckwith JG, Greenwald RM, et al. Head impact exposure in male and female collegiate ice hockey players. J Biomech 2014;47:109-14.

15 Young TJ, Daniel RW, Rowson S, et al. Head impact exposure in youth football: elementary school ages 7-8 years and the effect of returning players. Clin J Sport Med 2013 Epub ahead of print.

16 Patton DA, McIntosh AS, Kleiven S. The biomechanical determinants of concussion: finite element simulations to investigate brain tissue deformations during sporting impacts to the unprotected head. J App/ Biomech 2013;29:721-30.

17 Martini D, Eckner JT, Kutcher J, et al. Subconcussive head impact biomechanics: comparing differing offensive schemes. Med Sci Sports Exerc 2013;45:755-61.

18 Broglio SP, Puetz TW. The effect of sport concussion on neurocognitive function, self-report symptoms and postural control. Sports Med 2008;38:53-67.

19 Belanger HG, Vanderploeg RD. The neuropsychological impact of sports-related concussion: a meta-analysis. J Int Neuropsycho/ Soc 2005;11:345-57.

20 Iverson GL, Brooks BL, Collins MW, et al. Tracking neuropsychological recovery following concussion in sport. Brain Inj 2006;20:245-52.

21 Iverson GL. Mild traumatic brain injury meta-analyses can obscure individual differences. Brain Inj 2010;24:1246-55. 
22 Collins M, Lovell MR, Iverson GL, et al. Examining concussion rates and return to play in high school football players wearing newer helmet technology: a three-year prospective cohort study. Neurosurgery 2006;58:275-86.

23 Collins MW, Iverson GL, Gaetz M, et al. Sport-related concussion. In: Zasler ND, Katz DI, Zafonte RD. eds. Brain injury medicine: principles and practice. New York: Demos Medical Publishing, 2012: 498-516.

24 King DA, Hume PA, Milburn P, et al. Rugby league injuries in New Zealand: a review of 8 years of Accident Compensation Corporation injury entitlement claims and costs. Br J Sports Med 2009;43:595-602.

25 Gabbett TJ. Incidence of injury in junior rugby league players over four competitive seasons. J Sci Med Sport 2008;11:323-8.

26 Hodgson L, Standen PJ, Batt ME. An analysis of injury rates after the seasonal change in rugby league. Clin J Sport Med 2006;16:305-10.

27 King DA, Gabbett TJ, Dreyer C, et al. Incidence of injuries in the New Zealand national rugby league sevens tournament. J Sci Med Sport 2006;9:110-18.

28 Gabbett TJ. Influence of playing position on the site, nature, and cause of rugby league injuries. J Strength Cond Res 2005;19:749-55.

29 Gabbett TJ. Influence of the limited interchange rule on injury rates in sub-elite rugby league players. I Sci Med Sport 2005;8:111-15.

30 Gabbett TJ, Domrow N. Risk factors for injury in subelite rugby league players. Am J Sports Med 2005;33:428-34.

31 Gabbett TJ. Reductions in pre-season training loads reduce training injury rates in rugby league players. Br J Sports Med 2004;38:743-9.

32 Hrysomallis C. Impact energy attentuation of protective football headgear against a yielding surface. J Sci Med Sport 2004;7:156-64.

33 Gabbett TJ. Influence of training and match intensity on injuries in rugby league. J Sports Sci 2004;22:409-17.

34 McIntosh A, McCrory P, Finch CF. Performance enhanced headgear: a scientific approach to the development of protective headgear. Br J Sports Med 2004;38:46-9.

35 Gissane C, White J, Kerr K, et al. Health and safety implications of injury in professional rugby league football. Occup Med 2003;53:512-17.

36 Gissane $C$, Jennings $D$, Kerr K, et al. Injury rates in rugby league football: impact of change in playing season. Am J Sports Med 2003;31:954-8.

37 Gabbett TJ. Incidence of injury in semi-professional rugby league players. Br J Sports Med 2003;37:36-43.

38 Gabbett TJ. Incidence of injury in amateur rugby league sevens. Br J Sports Med 2002;36:23-6.

39 Gissane $C$, Jennings $D$, White J, et al. Injury in summer rugby league football: the experiences of one club. Br J Sports Med 1998;32:149-52.

40 Gissane C, Jennings DC, Cumine AJ, et al. Differences in the incidence of injury between rugby league forwards and backs. Aust J Sci Med Sport 1997;29:91-4.

41 Gibbs N. Injuries in professional rugby league. A three-year prospective study of the South Sydney Professional Rugby League Football Club. Am J Sports Med 1993;21:696-700.

42 Seward $\mathrm{H}$, Orchard J, Hazard $\mathrm{H}$, et al. Football injuries in Australia at the elite level. Med J Aust 1993;159:298-301.

43 McKenna S, Borman B, Findlay J, et al. Sports injuries in New Zealand. N Z Med J 1986;99:899-901.

44 Alexander D, Kennedy M, Kennedy J. Injuries in rugby league football. Med J Aust $1979 ; 2: 341-2$

45 Lingard DA, Sharrock NE, Salmond CE. Risk factors of sports injuries in winter. N Z Med J 1976;83:69-73.

46 Gissane C, Hodgson L, Jennings D. Time-loss injuries versus non-time-loss injuries in the first team rugby league football: a pooled data analysis. Clin J Sport Med 2012;22:414-17.

47 O'Connor D. NRL injury report 2010. Sport Health 2011;29:17-25.

48 O'Connor D. NRL injury report 2011. Sport Health 2012;30:12-22.

49 King $D$, Hume $P$, Clark T. Player perspectives on return to play after a match or training injury in amateur rugby league. N Z J Sports Med 2010;37:48-55.

50 King $D$, Hume $P$, Milburn $P$, et al. Rugby league injuries in New Zealand: variations in injury claims and costs by ethnicity, gender, age, district, body site, injury type and occupation. N Z J Sports Med 2009;36:48-55.

51 King D. Incidence of injuries in the 2005 New Zealand national junior rugby league competition. N Z J Sports Med 2006;34:21-7.
52 King DA, Gabbett TJ. Injuries in the New Zealand semi-professional rugby league competition. N Z J Sports Med 2009;36:6-15.

53 Norton R, Wilson M. Rugby league injuries and patterns. N Z J Sports Med 1995:22:37-8.

54 Hume PA, Marshall SW. Sports injuries in New Zealand: exploratory analyses. N Z J Sports Med 1994;22:18-22.

55 Hinton-Bayre AD, Geffen G, Friis P. Presentation and mechanisms of concussion in professional rugby league football. J Sci Med Sport 2004;7:400-4.

56 Hinton-Bayre AD, Geffen G. Severity of sports-related concussion and neuropsychological test performance. Neurology 2002;59:1068-70.

57 Hinton-Bayre AD, Geffen G, McFarland K. Mild head injury and speed of information processing: a prospective study of professional rugby league players. J Clin Exp Neuropsychol 1997;19:275-89.

58 McCrory PR, Bladin PF, Berkovic SF. Retrospective study of concussive convulsions in elite Australian rules and rugby league footballers: phenomenology, aetiology, and outcome. BMJ 1997;314:171-4.

59 King D, Clark T, Gissane C. Use of a rapid visual screening tool for the assessment of concussion in amateur rugby league: a pilot study. J Neurol Sci 2012;320:16-21.

60 King $D$, Hume $P$, Clark T. First-aid concussion knowledge of rugby league team management, administrators and officials in New Zealand. N Z J Sports Med 2010;37:56-68

61 King D, Hume PA, Clark T. Nature of tackles that result in injury in professional rugby league. Res Sports Med 2012;20:86-104.

62 Stephenson S, Gissane C, Jennings D. Injury in rugby league: a four year prospective survey. Br J Sports Med 1996;30:331-4.

63 King DA, Gabbett TJ. Amateur rugby league match injuries in New Zealand. N Z J Sports Med 2009;36:16-21.

64 McLellan CP, Lovell DI, Gass GC. Biochemical and endocrine responses to impact and collision during elite rugby league match play. J Strength Cond Res 2011;25:1553-62.

65 King DA, Gabbett TJ, Gissane C, et al. Epidemiological studies of injuries in rugby league: suggestions for definitions, data collection and reporting methods. J Sci Med Sport 2009;12:12-19.

66 McCrory P, Meeuwisse W, Johnston K, et al. Consensus statement on concussion in sport-the 3rd international conference on concussion in sport held in Zurich, November 2008. J Sci Med Sport 2009;12:340-51.

67 McCrory $\mathrm{P}$, Johnston $\mathrm{K}$, Meeuwisse $\mathrm{W}$, et al. Summary and agreement statement of the 2nd international conference on concussion in sport, Prague 2004. Br J Sports Med 2005;39:196-204.

68 Aubry M, Cantu R, Dvorak J, et al. Summary and agreement statement of the first international conference on concussion in sport, Vienna 2001. Br J Sports Med 2002;36:6-10.

69 Moser RS, Iverson GL, Echemendia RJ, et al. Neuropsychological evaluation in the diagnosis and management of sports-related concussion. Arch Clin Neuropsychol 2007;22:909-16.

70 Giza CC, Kutcher JS, Ashwal S, et al. Summary of evidence-based guideline update: evaluation and management of concussion in sports: report of the Guideline Development Subcommittee of the American Academy of Neurology. Neurology 2013;80:2250-7

71 McCrory P, Meeuwisse WH, Aubry M, et al. Consensus statement on concussion in sport: the 4th international conference on concussion in sport held in Zurich, November 2012. Br J Sports Med 2013;47:250-8

72 Hutchison MG, Comper P, Meeuwisse WH, et al. A systematic video analysis of National Hockey League (NHL) concussions, part I: who, when, where and what? Br J Sports Med 2013; Epub ahead of print(PubMed PMID: 23766438).

73 Hutchison MG, Comper P, Meeuwisse WH, et al. A systematic video analysis of National Hockey League (NHL) concussions, part II: how concussions occur in the NHL. Br J Sports Med 2013; Epub ahead of print(PubMed PMID: 23637116).

74 Ranson, Peirce N, Young M. Batting head injury in professional cricket: a systematic video analysis of helmet safety characteristics. Br J Sports Med 2013:47:644-8.

75 Lincoln AE, Caswell SV, Almquist JL, et al. Video incident analysis of concussions in boys' high school lacrosse. Am J Sports Med 2013;41:756-61.

76 Koh JO, Watkinson EJ, Yoon YJ. Video analysis of head blows leading to concussion in competition Taekwondo. Brain Inj 2004;18:1287-96. 